\title{
Atualização no estadiamento dos sarcomas ósseos e das partes moles*
}

\section{Updating in the Staging of Bone and Soft Tissue Sarcomas}

\author{
Alex Guedes ${ }^{1 \odot}$ Marcelo Bragança dos Reis Oliveira ${ }^{20}$ \\ ${ }^{1}$ Serviço de Ortopedia, Hospital Santa Izabel, Santa Casa de \\ Misericórdia da Bahia, Salvador, BA, Brasil \\ ${ }^{2}$ Serviço de Traumato-ortopedia, Hospital Universitário Clementino Fraga \\ Filho, Universidade Federal do Rio de Janeiro, Rio de Janeiro, RJ, Brasil \\ ${ }^{3}$ Departamento de Radiologia, Universidade Federal Fluminense, \\ Niterói, RJ, Brasil \\ Rev Bras Ortop 2021;56(4):411-418.
}

Flávia Martins Costa ${ }^{3(1)}$ Adelina Sanches de Melo4잉

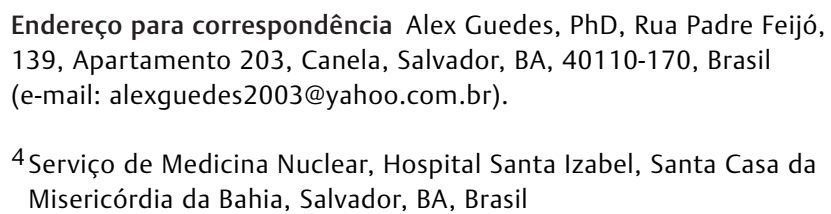

Endereço para correspondência Alex Guedes, PhD, Rua Padre Feijó, 139, Apartamento 203, Canela, Salvador, BA, 40110-170, Brasil (e-mail: alexguedes2003@yahoo.com.br).

${ }^{4}$ Serviço de Medicina Nuclear, Hospital Santa Izabel, Santa Casa da Misericórdia da Bahia, Salvador, BA, Brasil

\section{Resumo \\ Palavras-chave \\ - estadiamento de neoplasias \\ - sarcoma \\ - neoplasias de tecido conjuntivo \\ - neoplasias de tecido ósseo \\ - diagnóstico por imagem \\ - patologia cirúrgica}

Os sarcomas ósseos e das partes moles consistem em grupo heterogêneo de neoplasias malignas de origem mesenquimal que podem ocorrer em qualquer faixa etária. O estadiamento preciso destas lesões determina as melhores estratégias terapêuticas e estimativas de prognóstico. Dois sistemas de estadiamento são os mais frequentemente empregados no manejo destas neoplasias: o sistema proposto pelo grupo da Universidade da Flórida, liderado pelo Dr. William F. Enneking (1980), adotado pela Musculoskeletal Tumor Society (MSTS) e o sistema desenvolvido pela American Joint Committee on Cancer (AJCC) (1977) que se encontra em sua 8 a edição (2017). O presente artigo busca atualizar o leitor a respeito do estadiamento dos sarcomas ósseos e das partes moles que acometem o sistema musculoesquelético.

Bone and soft tissue sarcomas consist of a heterogeneous group of malignant tumors of mesenchymal origin that can affect patients from any age. The precise staging of these lesions determines the best therapeutic strategies and prognosis estimates. Two staging systems are the most frequently used: the system proposed by the University of Florida group, led by Dr. William F. Enneking (1980) and adopted by the Musculoskeletal Tumor Society (MSTS), and the system developed by the American Joint Committee on Cancer (AJCC) (1977), currently in its $8^{\text {th }}$ edition (2017). This paper updates the reader on the staging of bone and soft tissue sarcomas affecting the musculoskeletal system.

\footnotetext{
Trabalho desenvolvido no Grupo de Oncologia Ortopédica, Serviço de Ortopedia, Hospital Santa Izabel, Santa Casa de Misericórdia da Bahia, Salvador, BA, Brasil e no Serviço de Traumato-ortopedia do Hospital Clementino Fraga Filho, Universidade Federal do Rio de Janeiro, Rio de Janeiro, RJ, Brasil.
}

DOI https://doi.org/ 10.1055/s-0040-1710331. ISSN 0102-3616. (c) 2020. Sociedade Brasileira de Ortopedia e Traumatologia. All rights reserved.

This is an open access article published by Thieme under the terms of the Creative Commons Attribution-NonDerivative-NonCommercial-License, permitting copying and reproduction so long as the original work is given appropriate credit. Contents may not be used for commercial purposes, or adapted, remixed, transformed or built upon. (https://creativecommons.org/ licenses/by-nc-nd/4.0/)

Thieme Revinter Publicações Ltda., Rua do Matoso 170, Rio de Janeiro, RJ, CEP 20270-135, Brazil 


\section{Introdução}

Os sarcomas ósseos e das partes moles acometem, respectivamente, 1 e 5 pacientes a cada 100.000 indivíduos/ano. Juntos, correspondem a $\sim 1 \%$ de todas as neoplasias malignas que acometem o ser humano. ${ }^{1}$

As manifestações clínicas mais frequentes dos sarcomas ósseos e das partes moles - respectivamente, dor e aumento de volume do segmento acometido - tornam o ortopedista, frequentemente, o primeiro especialista a avaliar estes pacientes. Diante da suspeita clínica, o acompanhamento especializado, mediante realização de exames de imagem apropriados ao estadiamento e ao planejamento e execução da biópsia, permitirão o diagnóstico preciso e oportuno e a rápida instituição do tratamento adequado, fundamental à preservação do membro acometido e à cura da doença.

Por definição, sarcomas possuem o potencial para o desenvolvimento de metástases, ${ }^{2}$ o que impacta no prognóstico dos portadores destas neoplasias.

$O$ estadiamento consiste na abordagem ao paciente do exame inicial ao diagnóstico histológico e classificação definitiva de uma neoplasia. ${ }^{2}$

Há décadas, o estadiamento tem constituído instrumento crítico nas estimativas de prognóstico, fundamentando decisões relacionadas às opções terapêuticas, e estratificando pacientes em categorias de risco para ensaios clínicos. ${ }^{2,3} \mathrm{~A}$ Union for International Cancer Control (UICC) definiu os principais objetivos do estadiamento: guiar o planejamento terapêutico; estimar o prognóstico; auxiliar na avaliação dos resultados do tratamento; tornar a comunicação interinstitucional eficaz; e contribuir para a pesquisa científica. ${ }^{4}$

O estadiamento do câncer é considerado crítico para o controle da doença. ${ }^{5}$ Diversos sistemas foram descritos para o estadiamento dos tumores malignos primários que acometem o sistema musculoesquelético. ${ }^{3-12}$ Entretanto, o sistema proposto por Enneking et al., adotado pela Musculoskeletal Tumor Society(MSTS), ${ }^{6}$ e o sistema desenvolvido pelo American Joint Committee on Cancer (AJCC) ${ }^{8,9}$ são os mais utilizados na prática clínica. $O$ presente artigo busca atualizar o leitor a respeito do estadiamento destas lesões, utilizando o sistema Enneking/MSTS ${ }^{6}$ e a $8^{\text {a }}$ edição $(2017)^{8,9}$ da classificação TNM (Tumor, Node, Metastasis) (AJCC).

\section{O Papel da imagiologia e da patologia na avaliação dos sarcomas ósseos e das partes moles}

As neoplasias que afetam o sistema musculoesquelético são diagnosticadas em pelo menos um dos seguintes cenários clínicos: dor, proeminência óssea, massa palpável nas partes moles, fratura patológica, ou achado incidental em exames de imagem. ${ }^{12}$

História clínica e exame físico são frequentemente suficientes para levantar a suspeita de um tumor musculoesquelético, embora o exame radiográfico seja o meio mais comum de revelá-lo. ${ }^{13,14}$

A imagiologia é utilizada nas etapas de detecção, diagnóstico e diagnóstico diferencial, e na avaliação (estadiamento) das neoplasias musculoesqueléticas malignas primárias. ${ }^{13}$
Radiografias simples, tomadas em incidências ortogonais, propiciam informações referentes à aparência, extensão intraóssea, matriz tumoral, e margens entre o tumor e osso hospedeiro. Destruição cortical e reação periosteal estão associadas a neoplasias ósseas invasivas. ${ }^{14,15}$ Ao avaliar tumores de partes moles, as radiografias permitem detectar e definir o padrão de mineralização da lesão, auxiliando no diagnóstico/diagnóstico diferencial com outros tumores ou lesões pseudotumorais (miosite ossificante, calcinose tumoral, malformações vasculares, gota, condrossarcoma mesenquimal extraesquelético, osteossarcoma extraesquelético, lipossarcoma e sarcoma sinovial), além de prover valiosa informação sobre a densidade tumoral (tumores adipocíticos) e eventual envolvimento do osso subjacente. ${ }^{14,16}$

Diante do diagnóstico de lesão óssea ou das partes moles com características clínicas e radiográficas de agressividade biológica, é necessário realizar exames de imagem adicionais, ${ }^{12}$ buscando informações sobre extensão local, disseminação à distância (metástases) e diagnóstico histológico destas lesões (-Figura 1).

\section{Estadiamento local}

A extensão local de um sarcoma é definida pelos espaços anatômicos envolvidos. A compreensão da anatomia topográfica relevante é fundamental na definição da melhor abordagem terapêutica a cada situação clínica. ${ }^{17}$

Nos segmentos apendiculares, cápsula e cartilagem articular, cortical e periósteo, septos fasciais, origens e inserções musculares atuam como barreiras naturais à disseminação neoplásica, definindo compartimentos - um tumor confinado a um compartimento é considerado intracompartimental, estágio inferior a uma lesão que rompe estas barreiras, tornando-se extracompartimental. Sarcomas crescem centrifugamente através de áreas de menor resistência e são contidos parcialmente por uma pseudocápsula, onde podem permanecer confinados - as células malignas, entretanto, costumam se estender para além desta - se isto ocorre, mas o tumor permanece confinado a determinado compartimento anatômico, este é considerado extracapsular e intracompartimental; se a lesão invade um compartimento adjacente, é classificada como extracompartimental. ${ }^{18}$

A capacidade de avaliação multiplanar e o contraste de partes moles propiciado pela ressonância magnética (RM) ou, quando esta modalidade está contraindicada ou indisponível, ${ }^{8,11}$ da tomografia computadorizada (TC) contrastada, tornaram estas modalidades indispensáveis no estadiamento local $^{19}$ - eventualmente, RM e TC podem ser solicitadas em conjunto, por propiciarem informações complementares que auxiliam no delineamento das lesões em estudo. ${ }^{17}$ É importante mencionar que estes exames devem ser realizados antes da biópsia, para evitar artefatos que interfiram na interpretação das imagens. ${ }^{20}$

A RM é considerada superior à TC no estadiamento local dos sarcomas ósseos e constitui o pilar na avaliação por imagens dos sarcomas de partes moles. ${ }^{20}$ Os fatores determinantes para o estadiamento, referentes à morfologia da lesão, são tamanho e extensão local, ${ }^{21}$ melhor avaliados através da RM com 


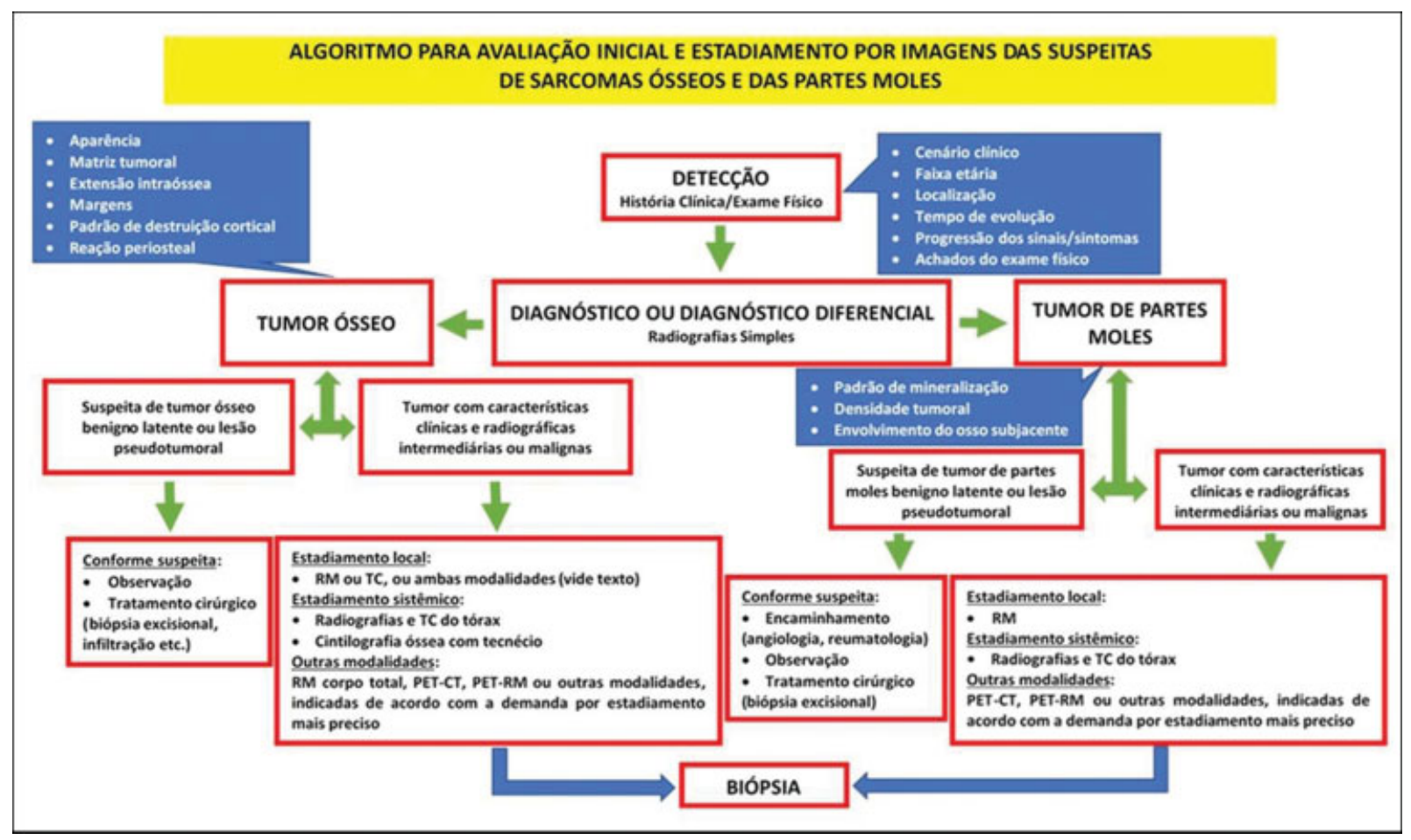

Fig. 1 Algoritmo para avaliação inicial e estadiamento por imagens das suspeitas de sarcomas ósseos e das partes moles.

gadolínio, utilizando técnicas avançadas de perfusão e difusão, ${ }^{19}$ o que permite determinar a configuração, localização, profundidade, tamanho e extensão local destas lesões e sua relação com músculos isolados, compartimentos musculares, planos fasciais, estruturas neurovasculares, articulações e órgãos situados em sua proximidade (- Figuras 2 e 3). ${ }^{15,18}$ É mandatório obter imagens de todo o segmento anatômico acometido (osso inteiro), para definir a extensão do envolvimento intramedular e identificar eventuais tumores ósseos descontínuos (skip metastasis), cuja presença guarda implicações importantes no prognóstico. 6,11,14,15,20

Ao avaliar sarcomas ósseos, a opção por RM ou TC pode basear-se nos achados radiográficos. Se há destruição cortical e tumor extracompartimental, a RM é a modalidade mais desejável, por proporcionar excelente contraste nas partes moles e determinar a extensão extraóssea do tumor melhor que a TC. ${ }^{19}$ A RM permite estadiamento mais acurado por sua capacidade de imageamento multiplanar (sagital, coronal, axial e oblíquo) e ausência de artefatos de endurecimento de feixe a partir do osso cortical, que ocorrem ao utilizarmos TC. ${ }^{19}$ Apesar de raramente útil em diagnósticos específicos, a TC é indicada quando não há evidência radiográfica de extensão do tumoral para as partes moles, por permitir visualizar mais claramente calcificação, detectar reação periosteal, invasão sutil ou destruição da cortical e determinar a extensão intraóssea da neoplasia.,19 A TC ainda é útil em delinear tumores em estruturas anatômicas complexas como esqueleto axial e cinturas pélvica e escapular, além de permitir melhor e mais compreensível demonstração dos sarcomas ósseos de superfície, tais como o osteossarcoma parosteal ou o condrossarcoma justa cortical, através da reconstrução tridimensional. ${ }^{19}$

\section{Estadiamento sistêmico}

A disseminação à distância constitui o principal fator prognóstico para os sarcomas ósseos e das partes moles. Sarcomas

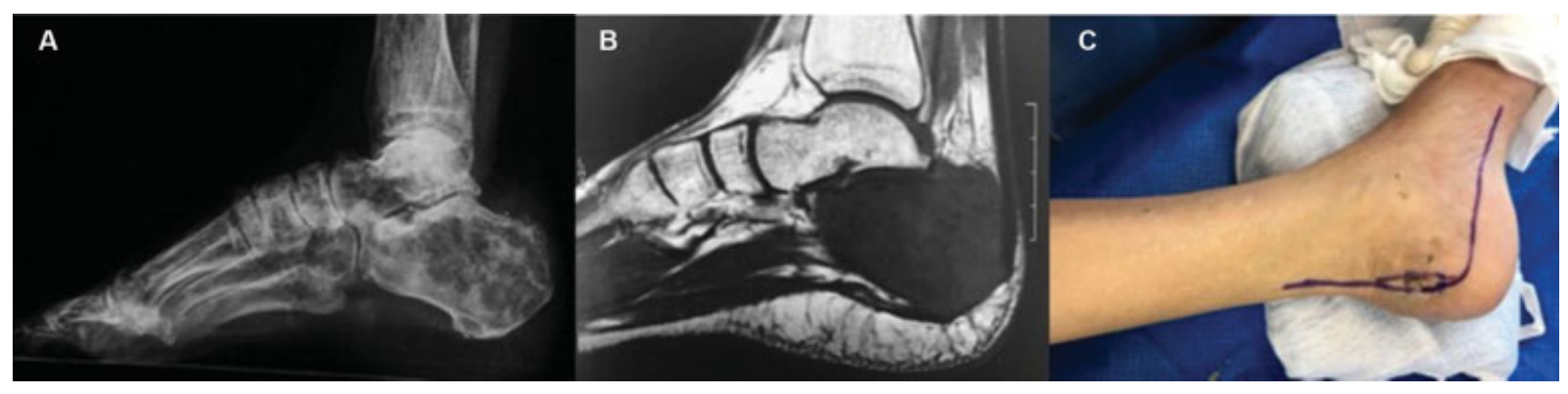

Fig. 2 Osteossarcoma convencional no calcâneo. (A) radiografia em perfil mostrando áreas líticas e escleróticas no calcâneo (B) corte sagital de ressonância magnética com sequência ponderada em T1 evidenciando hipossinal difuso no calcâneo sem tumor extracompartimental (C) via de acesso para ressecção do calcâneo. Estadiamento MSTS IA, AJCC IIA. 


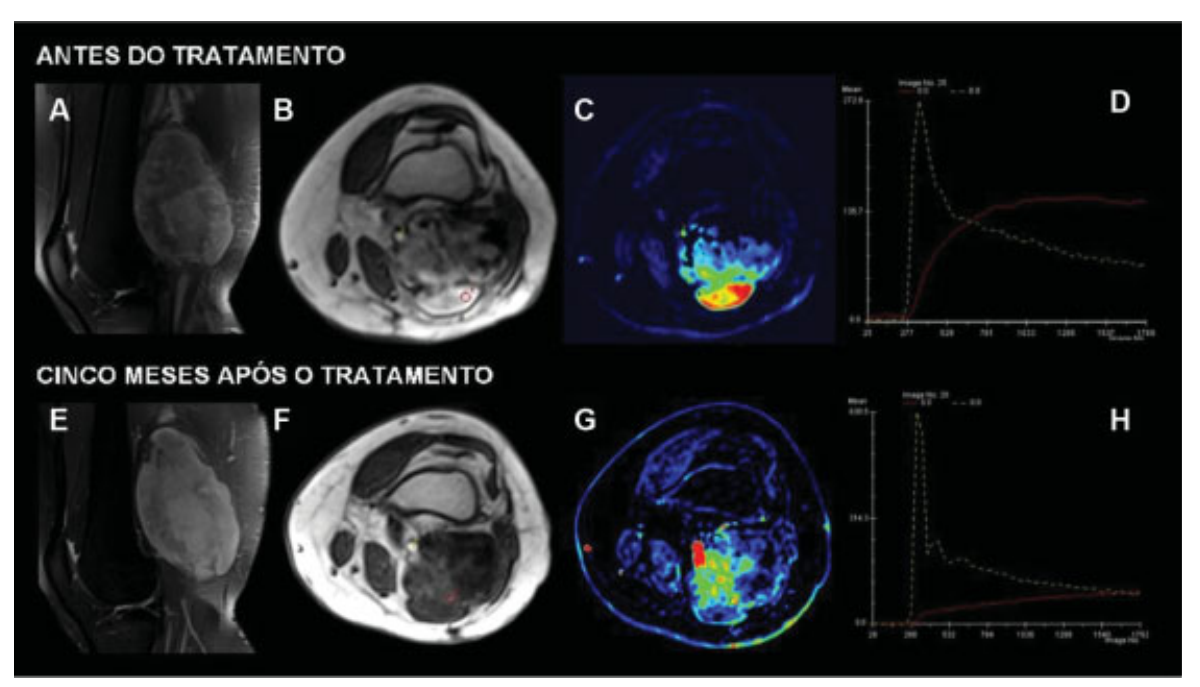

Fig. 3 Sarcoma pleomórfico de alto grau no joelho direito. Sequências em densidade protônica com supressão de gordura no plano sagital antes do tratamento (A) demonstrando lesão heterogênea no compartimento posterior. Estudo dinâmico axial (B) e mapa colorido (C) demonstrando realce precoce na porção posterior e superficial da lesão (linha vermelha em D). Cinco meses após o tratamento, a ressonância magnética convencional não evidencia mudança significativa na intensidade de sinal da lesão (E). Entretanto, o estudo dinâmico axial (F) e mapa colorido (G) evidenciam mudança no padrão do realce da lesão (linha vermelha em $\mathrm{H}$ ), indicando boa resposta ao tratamento. Análise histológica evidenciou mais de $90 \%$ de necrose tumoral. Estadiamento AJCC IIIA.

possuem via de difusão preferencial hematogênica - pulmão e esqueleto são os sítios mais frequentes para o desenvolvimento de metástases. Apesar de menos frequente, o comprometimento linfático tem importância no prognóstico alguns subtipos histológicos de sarcomas de partes moles costumam disseminar para linfonodos locorregionais (sarcoma sinovial, sarcoma epitelioide, sarcoma de células claras e angiossarcoma) ${ }^{14,22}$

Na avaliação do pulmão, são utilizadas radiografias do tórax, tomadas em duas incidências, e/ou, preferencialmente, ${ }^{8}$ TC do tórax de alta resolução, mais sensível na detecção de lesões. ${ }^{2,11,14}$

A National Comprehensive Cancer Network (NCCN) recomenda a realização de TC do abdômen e pelve no estadiamento de alguns sarcomas das partes moles com propensão para metástases nestes sítios: lipossarcoma mixoide, sarcoma epitelioide, leiomiossarcoma e angiossarcoma. 14,23,24

No estadiamento de sarcomas ósseos, a cintilografia óssea deve ser obtida para mapear o esqueleto em busca de lesões similares ou doença óssea metastática. ${ }^{2,8} \mathrm{O}$ mapeamento ósseo não é indicado rotineiramente no estadiamento inicial dos sarcomas das partes moles. ${ }^{14}$

A indicação rotineira de RM de corpo total, ${ }^{2}$ PET-CT $^{2,8}$ ou PET-MR ${ }^{2}$ ainda está sob avaliação no estadiamento dos sarcomas ósseos e das partes moles. Entretanto, quando necessárias, modalidades de imagem adicionais podem ser realizadas na avaliação de sítios suspeitos, considerando que o exato estadiamento da doença possui impacto no tratamento e no desfecho clínico. ${ }^{2}$

\section{Diagnóstico histológico}

A biópsia completa o processo de estadiamento clínico, ${ }^{8}$ confirmando o diagnóstico e determinando o grau histológico dos sarcomas pelo exame anatomopatológico, comple- mentado pela imunohistoquímica e biologia molecular, quando necessário.

Pacientes com suspeita de sarcoma devem ser preferencialmente biopsiados em um centro de referência com expertise no manejo dos sarcomas. ${ }^{8} \mathrm{~A}$ avaliação por imagens deve preceder a realização da biópsia. ${ }^{8,20}$

Uma amostra da neoplasia deve ser obtida através de biópsia percutânea com trefina (core needle), guiada pelo método de imagem apropriado (ultrassonografia, TC, fluoroscopia, etc.), ou mediante biópsia incisional. A localização da biópsia deve ser planejada cuidadosamente para permitir a ressecção de todo o seu trajeto em conjunto com a peça cirúrgica, no momento da ressecção definitiva do tumor. ${ }^{8}$

Subtipo e grau histológico permitem prever o comportamento biológico da neoplasia, variável com maior impacto no risco para disseminação metastática e na sobrevida geral. ${ }^{11} \mathrm{O}$ grau histológico correlaciona-se com o padrão de proliferação celular, atividade mitótica e o potencial metastático do tumor.

Sarcomas são classificados histologicamente como de alto ou baixo grau de acordo com a presença de atipia celular, número de figuras de mitose, grau de necrose e vascularização. ${ }^{22}$ Frequentemente, lesões de baixo grau são biologicamente menos ativas, possuem potencial metastático mínimo, requerem tratamento cirúrgico menos radical e não têm indicação para adjuvância mediante quimio e/ou radioterapia - estes tratamentos costumam ser inefetivos, devido à reduzida proliferação celular. Por outro lado, lesões de alto grau frequentemente necessitam de tratamento local e sistêmico mais radical, devido ao comportamento biológico agressivo. ${ }^{22}$

\section{Sistema de estadiamento da Musculoskeletal Tumor Society(MSTS)}

En 1980, a MSTS adotou o sistema de estadiamento cirúrgico dos sarcomas do sistema musculoesquelético criado em 
Gainesville, em 1977, pelo grupo da Universidade da Flórida de liderado pelo Dr. William F. Enneking, a partir de dados coletados entre os anos de 1968 a 1976., ${ }^{5,6}$ Este sistema baseia-se na definição da extensão tumoral em relação aos limites anatômicos e na graduação histológica, reunindo os fatores prognósticos mais importantes em uma classificação concisa para estimar a sobrevida, guiar o tratamento cirúrgico e servir como diretriz para a indicação de terapias adjuvantes. ${ }^{5,6}$ O seu desenvolvimento, baseado em observações cirúrgicas, torna os parâmetros intuitivos, facilitando o planejamento operatório. É o sistema mais utilizado por oncologistas ortopédicos, porém menos utilizado no estadiamento dos sarcomas das partes moles, sobretudo por oncologistas clínicos, cirurgiões oncológicos e outros especialistas. ${ }^{11}$

Este sistema considera a combinação de três variáveis: grau histopatológico da neoplasia ( $\mathrm{I}=$ baixo grau, II = alto grau); extensão local, para além do compartimento de origem ( $\mathrm{A}=$ intracompartimental, $\mathrm{B}=$ extracompartimental) e presença de metástases à distância (III) (- Tabela 1)., ${ }^{5,6}$ Lesões de baixo grau (I) correspondem às classes 1 ou 2 de Broder (baixa taxa mitótica, baixa proporção núcleo/citoplasma, pleomorfismo limitado, baixo risco $[<25 \%]$ para metástases). Lesões de alto grau (II) correspondem às classes 3 e 4 de Broder (figuras de mitose, nucleólos proeminentes, pleomorfismo, maior incidência de metástases). As subcategorias A (intracompartimental)e B (extracompartimental) são definidas pela avaliação por imagens do segmento afetado. O estágio III representa qualquer tumor com metástase à distância, definido pela avaliação por imagens. 5,6 $^{-}$

O estadiamento determina a extensão da ressecção cirúrgica, considerando a viabilidade para obtenção de margens oncológicas adequadas. Em geral, uma lesão de alto grau é biologicamente mais agressiva, portanto, possui maior probabilidade de invadir tecidos circundantes - isto coloca o paciente em maior risco para recidiva local e metástase; o uso de terapias adjuvantes é então preconizado para erradicar as células tumorais que permaneceriam após a ressecção cirúrgica. ${ }^{6}$

Como principais desvantagens do sistema MSTS enumeramos: 1. não inclui a variável tamanho em seu escopo, implicada como fator prognóstico importante para diversos subtipos de sarcomas de partes moles (lesões maiores costumam ter maior potencial metastático e podem beneficiarse da quimioterapia neoadjuvante $)^{5} ; 2$. possui limitado poder prognóstico discriminatório para estratos intermediários, por conta da dicotimização simplificada das variáveis (grau histológico, extensão local e à distância), que tende a agrupar a maior parte dos osteossarcomas e sarcomas de Ewing em um mesmo estágio; no osteossarcoma, a maioria dos pacientes é enquadrada no estágio IIB; no caso dos sarcomas de Ewing, a limitação é mais evidente por constituir neoplasia maligna de alto grau - o parâmetro grau histológico não é variável, impedindo a classificação no estágio $\mathrm{IA}^{10} ; 3$. Lesões originadas no crânio possuem comportamento clínico diferente e não podem ser classificadas por este sistema ${ }^{5} ; 4$. Não leva em conta a presença de um compartimento peridural contínuo nos tumores da coluna, variável que possui implicações neurológicas (possibilidade de sacrifício da medula e das raízes espinhais, e a necessidade de estabilização). ${ }^{5}$

\section{Sistema de estadiamento do American Joint Committee on Cancer(AJCC)}

O sistema de estadiamento proposto pelo AJCC para os sarcomas musculoesqueléticos, desde a descrição original do Manual for Staging of Cancer (MSC), em $1977,{ }^{25}$ sofreu atualizações e refinamentos com base na evolução das evidências científicas sobre o prognóstico e sobrevida associados a estas neoplasias.

\section{Estadiamento dos tumores ósseos malignos primários (AJCC)}

A 1aㅗ edição (1977) do $\mathrm{MSC}^{25}$ recomendava a utilização de protocolo para tumores ósseos malignos primários desenvolvido pela Task Force On Primary Malignant Bone Tumor no registro da identificação dos pacientes, história, dados clínicos, de imagem (radiografias), patológicos, histológicos (classificação para tumores ósseos primários e lesões pseudotumorais da Organização Mundial da Saúde (OMS) e das recidivas ou metástases no seguimento. Não indicava sistema específico para o estadiamento destas neoplasias, porém sugeria que estudos clínicos prospectivos, com maior número de casos, permitiriam criar uma classificação clínica satisfatória para o estadiamento e registro de desfechos, no futuro.

A partir da $2^{\underline{a}}$ edição ${ }^{26}$ (1983), o MSC passou a trazer um sistema para o estadiamento destas neoplasias, baseado no método TGNM: tamanho da neoplasia (T), grau histológico (G), presença ou ausência de metástase regional linfonodal $(\mathrm{N})$ e presença ou ausência de metástase à distância $(\mathrm{M})$. A esta altura, já eram definidos os estágios (IA, IB, IIA, IIB, III,

Tabela 1 Sistema de estadiamento adotado pela Musculoskeletal Tumor Society para os tumores musculoesqueléticos malignos, baseada no grau cirúrgico, extensão local, e presença ou ausência de metástases

\begin{tabular}{|l|l|l|l|}
\hline Estágio & Grau & Sítio & Metástase \\
\hline IA & Baixo (G1) & Intracompartmental (T1) & M0 \\
\hline IB & Baixo (G1) & Extracompartimental (T2) & M0 \\
\hline IIA & Alto (G2) & Intracompartimental (T1) & M0 \\
\hline IIB & Alto (G2) & Extracompartmental (T2) & M0 \\
\hline III & Qualquer G & Qualquer T & Metástases regionais ou à distância \\
\hline
\end{tabular}

Fonte: Enneking et al. ${ }^{6}$ 
IVA, IVB), com gradação prognóstica atribuída com base na avaliação combinada dessas variáveis.

Na 6 $6^{\mathfrak{a}}$ edição (2002) do MSC, ${ }^{21}$ até aquele momento, a extensão tumoral era definida como contida ou não no osso hospedeiro, assemelhando-se ao sistema Enneking/MSTS. O tamanho de oito centímetros tornou-se ponto de corte entre as designações T1 e T2, substituindo a classificação da extensão tumoral como intra ou extracompartimental. A escolha foi controversa, ${ }^{27}$ por basear-se na literatura relacionada ao sarcoma de Ewing, limitada para o osteossarcoma. Estudos posteriores confirmaram seu valor no estadiamento do sarcoma de Ewing ${ }^{28}$ e, até hoje, o MSC recomenda que o tamanho de nove centímetros constitui melhor indicador prognóstico para o osteossarcoma. A adição da designação T3 para tumores descontínuos (skip metastasis) ${ }^{9,16}$ foi outra modificação -Wuisman et al. ${ }^{29}$ compararam 224 pacientes que não possuíam skip metastasis ao diagnóstico com 23 pacientes que as possuíam - 22 destes últimos tiveram recidiva local ou metástase à distância, e faleceram; o uso de quimioterapia adjuvante não melhorou o prognóstico destes pacientes, impactando no prognóstico. A terceira atualização consistiu na diferenciação das metástases de acordo com a localização, distinguindo as pulmonares (IVA) das extrapulmonares (IVB) baseado nas evidências de melhor prognóstico para sarcomas ósseos associados a metástases pulmonares comparados àqueles com metástases para outros sítios ${ }^{30,31}$-a presença de múltiplas metástases pulmonares demonstrou pior prognóstico, embora não tenha se tornado parte de nenhum sistema de estadiamento até o momento. ${ }^{11,30}$

A $7^{\text {ạ }}$ edição do $\operatorname{MSC}^{32}$ (2010) restringiu a definição do estágio III apenas para tumores grau 3 (pouco diferenciado) e grau 4 (indiferenciado). O mesmo estadiamento foi empregado, independentemente do sítio primário, para os sarcomas ósseos e das partes moles.

A 8 ${ }^{a}$ edição (atual) do MSC, ${ }^{9}$ publicada em 2017, trouxe novas mudanças. A principal foi a inclusão de segmentos definidos do esqueleto axial como parte da classificação (T), perfazendo três sítios para sarcomas ósseos (i) esqueleto apendicular, tronco, ossos do crânio e faciais; (ii) coluna e (iii) pelve. Embora não afete o estadiamento desses tumores, isto permitiu determinar a estrutura para pesquisas futuras que aprimorem o sistema estudos mostraram evidências de que sarcomas ósseos com localização axial têm prognóstico marcadamente pior. ${ }^{33}$

Sarcomas ósseos e das partes moles foram descritos separadamente, de acordo com os sítios primários, principalmente devido a diferenças no prognóstico e estratégia de tratamento ( - Tabela 2). Outra modificação ocorreu na classificação do grau histopatológico $(G)$, que passou de quatro para três níveis, reservando o estágio III para G2-G3 (tumores de alto grau), eliminando a designação G4, conforme recomendação do American College of Pathologists, que utiliza o sistema da Fédération Nationale des Centres de LutteContreleCancer(FNCLCC) para classificar os sarcomas das partes moles, ${ }^{9}$ possibilitando uniformidade às classificações dos sarcomas ósseos e das partes moles. ${ }^{11}$

\section{Estadiamento dos sarcomas das partes moles (AJCC)}

O sistema de estadiamento AJCC para sarcomas das partes moles é o mais utilizado na estratificação de prognóstico e definição de abordagem destas neoplasias. Considera fatores adicionais na estimativa de prognóstico e possibilita melhor comunicação interdisciplinar. A presença de numerosos subtipos de sarcomas de partes moles demanda estadiamento mais complexo, o que não ocorre com os sarcomas ósseos, com poucos subtipos histológicos. ${ }^{11}$

Desde a $1^{\text {a }}$ edição (1977), ${ }^{25}$ o MSC já trazia o sistema TGNM para o estadiamento destas neoplasias, e, com base na avaliação combinada dessas variáveis, foram definidos os estágios IA, IB, IIA, IIB, IIIA, IIIB, IIIC, IVA e IVB, com graduação prognóstica atribuída. Esta classificação se manteve na $2^{\text {a }}$ edição do MSC (1983), ${ }^{26}$ e passou por mudanças paulatinas a

Tabela 2 Classificação da American Joint Committee on Cancer (AJCC) para sarcomas ósseos. Grupos de estágios prognósticos para sarcomas ósseos no esqueleto apendicular, tronco, crânio e ossos faciais (não existem grupos de estágios prognósticos AJCC para coluna e pelve)

\begin{tabular}{|l|l|l|l|l|}
\hline Estágio & Tumor primário (T) & Linfonodo regional (N) & Metástase à distância (M) & Grau histológico (G) \\
\hline IA & T1 & N0 & M0 & G1 ou GX \\
\hline IB & T2 ou T3 & N0 & M0 & G1 ou GX \\
\hline IIA & T1 & N0 & M0 & G2 ou G3 \\
\hline IIB & T2 & N0 & M0 & G2 ou G3 \\
\hline III & T3 & N0 & M0 & G2 ou G3 \\
\hline IVA & Qualquer T & N0 & M1a & Qualquer $\mathrm{G}$ \\
\hline IVB & Qualquer T & N1 & Qualquer M & Qualquer $\mathrm{G}$ \\
\hline & Qualquer T & Qualquer N & M1b & Qualquer $\mathrm{C}$ \\
\hline
\end{tabular}

Abreviações: G1, bem diferenciado, baixo grau; $G 2$, moderadamente diferenciado, alto grau; G3, pobremente diferenciado, alto grau; GX, o grau não pode ser acessado; M0, sem metástases à distância; M1a, metástases à distância (pulmão); M1b, metástases à distância (ossos ou outros sítios à distância); N0, sem metástases linfonodais regionais; N1, metástases linfonodais regionais; T0, não há evidência de tumor primário; T1, tumor $\leq 8 \mathrm{~cm} ; \mathrm{T} 2$, tumor $>8 \mathrm{~cm} ; \mathrm{T} 3$, tumores descontínuos no sítio ósseo primário; TX, o tumor primário não pode ser acessado.

Fonte: Amin MB, Edge S, Greene F, Byrd DR, Brookland RK, Washington MK, et al., eds. AJCC CancerStaging Manual. 8th ed. Switzerland: Springer; 2017. ${ }^{8}$ 
Tabela 3 Classificação AJCC para sarcomas de partes moles situados no tronco e extremidades. Grupos de estágiosprognósticos

\begin{tabular}{|l|l|l|l|l|}
\hline Estágio & Tumor primário (T) & Linfonodo regional (N) & Metástase à distância (M) & Grau histológico (G) \\
\hline IA & T1 & N0 & M0 & G1, GX \\
\hline IB & T2, T3, T4 & N0 & M0 & G1, GX \\
\hline II & T1 & N0 & M0 & G2, G3 \\
\hline IIIA & T2 & N0 & M0 & G2, G3 \\
\hline IIIB & T3, T4 & N0 & M0 & G2, G3 \\
\hline IV & Qualquer T & N1 & M0 & Qualquer G \\
\hline & Qualquer T & Qualquer N & M1 & Qualquer G \\
\hline
\end{tabular}

Abreviações: G1, diferenciação total, contagem mitótica e escore de necrose 2 ou 3; G2, diferenciação total, contagem mitótica e escore de necrose 4 ou 5; G3, diferenciação total, contagem mitótica e escore de necrose 6, 7 ou 8; GX, o grau não pode ser acessado; M0, sem metástases à distância; M1, metástases à distância; N0, sem metástases linfonodais regionais ou status linfonodal desconhecido; N1, metástases linfonodais regionais; T0, não há evidência de tumor primário; $T 1$, tumor $\leq 5 \mathrm{~cm}$ em sua maior dimensão; $T 2$, tumor $>5 \mathrm{~cm}$ e $\leq 10 \mathrm{~cm}$ em sua maior dimensão; T3, tumor $>10 \mathrm{~cm}$ e $\leq 15 \mathrm{~cm}$ em sua maior dimensão; T4, tumor $>15 \mathrm{~cm}$ em sua maior dimensão; TX, o tumor primário não pode ser acessado. Fonte: Amin MB, Edge S, Greene F, Byrd DR, Brookland RK, Washington MK, et al., eds. AJCC Cancer Staging Manual. 8th ed. Switzerland: Springer; $2017 .{ }^{8}$

partir da $3^{\text {a }}$ edição (1988), ${ }^{34}$ considerando o surgimento de novas evidências clínicas.

Na $6^{a}$ edição do manual AJCC, ${ }^{21}$ angiossarcoma e mesenquimoma maligno foram considerados exceções e removidos, enquanto o tumor estromal gastrointestinal (GIST) e o sarcoma de Ewing de partes moles foram adicionados. Além disso, os tumores G1-2, T2b, N0 M0 foram reclassificados como estágio I ao invés de estágio II.

$\mathrm{Na} 7^{\mathrm{a}}$ edição do manual AJCC, ${ }^{32}$ fibromatose, sarcoma de Kaposi, fibrossarcoma infantil e GIST foram removidos do sistema. A doença linfonodal $\mathrm{N} 1$ foi reclassificada como estágio IIIB ao invés de estágio IV, com base em evidências de nível IV - o estudo clássico de Fong et al. ${ }^{35}$ demonstrou que sarcomas de partes moles com linfonodos positivos apresentam taxa de sobrevida similar àquela da doença localmente avançada, porém melhor do que aquela associada à presença de metástases à distância. ${ }^{35-37} \mathrm{O}$ esquema de graduação histológica também foi alterado para três níveis, conforme preconizado pelo College of American Pathologists, baseado em evidências de nível II, onde observou-se que o sistema da FNCLCC prediz a sobrevida com precisão significativa. ${ }^{38}$ Foi também retirada da classificação a variável profundidade do tumor na determinação do estágio e prognóstico ${ }^{11}$ - as recomendações para descrição de tumores como superficiais ou profundos à fáscia foram mantidas, porém consideradas irrelevantes no estadiamento; no estudo de Rydholm et al., ${ }^{39}$ a profundidade não foi considerada fator prognóstico quando analisada independentemente do tamanho tumoral - outros estudos sugeriam pior sobrevida com tumores mais profundos, razão pela qual permaneceu como parte do estadiamento do sarcoma das partes moles por décadas; entretanto, quando realizadas análises mais detalhadas, a profundidade revelou-se variável de confusão - o tamanho é o verdadeiro fator independente associado ao pior prognóstico. ${ }^{33}$

Na 8 a edição do MSC (2017), ${ }^{9}$ quatro sítios tumorais foram descritos para os sarcomas das partes moles: (i) extremidades e tronco; (ii) retroperitôneo; (iii) cabeça e pescoço e (iv) sítios viscerais. Todas as referências à profundidade das lesões foram removidas, ${ }^{6}$ decisão baseada em evidências de nível II publicadas por Maki et al., ${ }^{23}$ que confirmaram que esta variável não constituiu fator de risco independente após realização de análise multivariada. Outra modificação consistiu no aumento do número de categorias de tamanho do tumor de duas $(\leq 5 \mathrm{~cm}$ ou $>5 \mathrm{~cm})$ para quatro $(\leq 5 \mathrm{~cm},>5$ / $\leq 10 \mathrm{~cm},>10 / \leq 15 \mathrm{~cm},>15 \mathrm{~cm})$. A decisão de agrupar T3 e T 4 $(>10 / \leq 15 \mathrm{~cm}$ e $>15 \mathrm{~cm})$ no estágio IIIB foi corroborada por evidência de nível II, proporcionada por estudo envolvendo 1.091 pacientes que mostrou que tumores divididos em categorias de tamanho de $\leq 5 \mathrm{~cm},>5 / \leq 10 \mathrm{~cm}$ e $>15 \mathrm{~cm}$ apresentam taxas de mortalidade marcadamente diferentes; este estudo não mostrou diferença significativa na sobrevida entre as categorias $>5 / \leq 10 \mathrm{~cm}$ e $>10 / \leq 15 \mathrm{~cm}^{40,41}$; ainda assim, a categorização de tamanho em quatro níveis foi incluída, de acordo com dados publicados no estudo de Maki et al., ${ }^{23}$ que demonstraram diferenças significativas na sobrevida global livre de recidiva local entre os quatro grupos e platô na sobrevida em tumores de $10 \mathrm{~cm}$. Esse achado foi apoiado por estudo recente, no qual nomogramas foram utilizados para prever a sobrevida global; para qualquer mudança unitária no tamanho dos tumores $>10 \mathrm{~cm}$, houve efeito marcadamente menor na sobrevida, quando comparado ao efeito sobre a sobrevida dos tumores $<10 \mathrm{~cm} .{ }^{24}$ Ainda na $8^{a}$ edição, a doença linfonodal N1 associada a tumores situados no tronco e extremidades foi reclassificada como estágio IV, provavelmente porque o prognóstico nestes casos é mais próximo à doença metastática qualquer TNOM1 do que qualquer TNOMO, mas permanece IIIB para tumores situados em outros sítios ${ }^{41}$ (-Tabela 3).

\section{Considerações finais}

O domínio do conhecimento sobre os sistemas de estadiamento dos sarcomas ósseos e das partes moles, assim como sobre os métodos de imagem e de diagnóstico e graduação histológica empregados na classificação destes tumores é de fundamental importância não só para os especialistas envolvidos diretamente no tratamento destes pacientes, mas também para os ortopedistas que frequentemente tornamse responsáveis por seu primeiro atendimento, cuja qualidade tem o potencial para interferir no desfecho clínico. 


\section{Conflito de Interesses}

Os autores declaram não haver conflito de interesses.

\section{Referências}

1 American Cancer Society. Cancer facts and figures 2017. Atlanta: American Cancer Society. Disponível em: https://www.cancer.org/research/cancer-facts-statistics/all-cancer-facts-figures/cancer-facts-figures-2017.html. [Acessado em 24 de Julho, 2019]

2 Mavrogenis AF, Angelini A, Vottis C, et al. State-of-the-art approach for bone sarcomas. Eur J Orthop Surg Traumatol 2015;25(01):5-15

3 Cates JM. Comparison of the AJCC, MSTS, and Modified Spanier Systems for Clinical and Pathologic Staging of Osteosarcoma. Am J Surg Pathol 2017;41(03):405-413

4 Brierley JD, Gospodarowicz MK, Wittekind CW, Eds. International Union Against Cancer: TNM Classification of Malignant Tumors. 8th ed. New Jersey, NY: Wiley-Blackwell; 2017

5 Jawad MU, Scully SP. In brief: classifications in brief: enneking classification: benign and malignant tumors of the musculoskeletal system. Clin Orthop Relat Res 2010;468(07):2000-2002

6 Enneking WF, Spanier SS, Goodman MA. A system for the surgical staging of musculoskeletal sarcoma. Clin Orthop Relat Res 1980; (153):106-120

7 Garcia Filho RJ. Estadiamento de Enneking dos tumores músculoesqueléticos. Rev Bras Ortop 1991;27(08):275-278

8 Kneisl JS, Rosenberg AE, Anderson PM, Antonescu CR, Bruland OS, Cooper K. Bone. In: Amin MB, Edge S, Greene F, Byrd DR, Brookland RK, Washington MK, et al., editors. AJCC Cancer Staging Manual. 8th ed. Switzerland: Springer; 2017:469-486

9 Pollock RE, Maki RG, Brookland RK, Agulnik M, Asare EA, Baldini EH. Soft Tissue Sarcoma. In: Amin MB, Edge S, Greene F, Byrd DR, Brookland RK, Washington MK, et al., eds. AJCC Cancer Staging Manual. 8th ed. Switzerland: Springer; 2017:487-545

10 Cates JMM. Simple staging system for osteosarcoma performs equivalently to the AJCC and MSTS systems. J Orthop Res 2018;36 (10):2802-2808

11 Steffner RJ, Jang ES. Staging of Bone and Soft-tissue Sarcomas. J Am Acad Orthop Surg 2018;26(13):e269-e278

12 Stacy GS, Mahal RS, Peabody TD. Staging of bone tumors: a review with illustrative examples. AJR Am J Roentgenol 2006;186(04):967-976

13 Greenspan A, Jundt G, Remagen W. Differential diagnosis in orthopaedic oncology. 2nd ed. Philadelphia, PA: Lippincott Williams \& Wilkins; 2006

14 Caracciolo JT, Letson GD. Radiologic Approach to Bone and Soft Tissue Sarcomas. Surg Clin North Am 2016;96(05):963-976

15 Peabody TD, Gibbs CP Jr, Simon MA. Evaluation and staging of musculoskeletal neoplasms. J Bone Joint Surg Am 1998;80(08): 1204-1218

16 Patel DB, Matcuk GR Jr. Imaging of soft tissue sarcomas. Linchuang Zhongliuxue Zazhi 2018;7(04):35

17 Liu PT, Valadez SD, Chivers FS, Roberts CC, Beauchamp CP. Anatomically based guidelines for core needle biopsy of bone tumors: implications for limb-sparing surgery. Radiographics 2007;27(01):189-205, discussion 206

18 Anderson MW, Temple HT, Dussault RG, Kaplan PA. Compartmental anatomy: relevance to staging and biopsy of musculoskeletal tumors. AJR Am J Roentgenol 1999;173(06):1663-1671

19 Costa FM, Canella C, Gasparetto E. Advanced magnetic resonance imaging techniques in the evaluation of musculoskeletal tumors. Radiol Clin North Am 2011;49(06):1325-1358, vii-viii vii-viii

20 Sajadi KR, Heck RK, Neel MD, et al. The incidence and prognosis of osteosarcoma skip metastases. Clin Orthop Relat Res 2004;(426): 92-96
21 Greene FL, Page DL, Fleming ID, et al. AJCC Manual for Staging of Cancer. 6th ed. Switzerland: Springer; 2002

22 Ferrari A, Dirksen U, Bielack S. Sarcomas of Soft Tissue and Bone. Prog Tumor Res 2016;43:128-141

23 Maki RG, Moraco N, Antonescu CR, et al. Toward better soft tissue sarcoma staging: building on american joint committee on cancer staging systems versions 6 and 7. Ann Surg Oncol 2013;20(11): 3377-3383

24 Callegaro D, Miceli R, Bonvalot S, et al. Development and external validation of two nomograms to predict overall survival and occurrence of distant metastases in adults after surgical resection of localised soft-tissue sarcomas of the extremities: a retrospective analysis. Lancet Oncol 2016;17(05):671-680

25 Beahrs OH, Carr DT, Rubin P, Eds. AJCC Manual for Staging of Cancer. Chicago, IL: American Joint Committee; 1977

26 Beahrs OH, Myers MH, Eds. AJCC Manual for Staging of Cancer. 2nd ed. Philadelphia, PA: Lippincott; 1983

27 Kim MS, Lee SY, Cho WH, et al. An examination of the efficacy of the $8 \mathrm{~cm}$ maximal tumor diameter cutoff for the subdivision of AJCC stage II osteosarcoma patients. J Surg Oncol 2008;98(06): 427-431

28 Lee J, Hoang BH, Ziogas A, Zell JA. Analysis of prognostic factors in Ewing sarcoma using a population-based cancer registry. Cancer 2010;116(08):1964-1973

29 Wuisman P, Enneking WF. Prognosis for patients who have osteosarcoma with skip metastasis. J Bone Joint Surg Am 1990; 72(01):60-68

30 Ward WG, Mikaelian K, Dorey F, et al. Pulmonary metastases of stage IIB extremity osteosarcoma and subsequent pulmonary metastases. J Clin Oncol 1994;12(09):1849-1858

31 Cotterill SJ, Ahrens S, Paulussen M, et al. Prognostic factors in Ewing's tumor of bone: analysis of 975 patients from the European Intergroup Cooperative Ewing's Sarcoma Study Group. J Clin Oncol 2000;18(17):3108-3114

32 Edge SB, Byrd DR, Compton CC, Fritz AG, Greene FL, Trotti A III. AJCC Manual for Staging of Cancer. 7th ed. New York, NY: Springer; 2010

33 Bielack SS, Kempf-Bielack B, Delling G, et al. Prognostic factors in high-grade osteosarcoma of the extremities or trunk: an analysis of 1,702 patients treated on neoadjuvant cooperative osteosarcoma study group protocols. J Clin Oncol 2002;20(03):776-790

34 Beahrs OH, Henson DE, Hutter RVP, Myers MH, Eds. AJCC Manual for Staging of Cancer. 3rd ed. Philadelphia, PA: Lippincott; 1988

35 Fong Y, Coit DG, Woodruff JM, Brennan MF. Lymph node metastasis from soft tissue sarcoma in adults. Analysis of data from a prospective database of 1772 sarcoma patients. Ann Surg 1993;217(01):72-77

36 Riad S, Griffin AM, Liberman B, et al. Lymph node metastasis in soft tissue sarcoma in an extremity. Clin Orthop Relat Res 2004; (426):129-134

37 Behranwala KA, A'Hern R, Omar AM, Thomas JM. Prognosis of lymph node metastasis in soft tissue sarcoma. Ann Surg Oncol 2004;11(07):714-719

38 Mariani L, Miceli R, Kattan MW, et al. Validation and adaptation of a nomogram for predicting the survival of patients with extremity soft tissue sarcoma using a three-grade system. Cancer 2005;103(02):402-408

39 Rydholm A, Gustafson P. Should tumor depth be included in prognostication of soft tissue sarcoma? BMC Cancer 2003; $3: 17$

40 Lahat G, Tuvin D, Wei C, et al. New perspectives for staging and prognosis in soft tissue sarcoma. Ann Surg Oncol 2008;15(10): 2739-2748

41 Tanaka K, Ozaki T. New TNM classification (AJCC eighth edition) of bone and soft tissue sarcomas: JCOG Bone and Soft Tissue Tumor Study Group. Jpn J ClinOncol 2019;49(02):103-107 